\title{
Analysis of Changes in Thermomechanical Properties and Structure of Polyamide Modified with Fly Ash from Biomass Combustion
}

\author{
Adam Gnatowski $^{1} \cdot$ Małgorzata Ulewicz $^{2} \cdot$ Mateusz Chyra $^{1}$
}

Published online: 7 March 2017

(C) The Author(s) 2017. This article is published with open access at Springerlink.com

\begin{abstract}
Study of performance of polyamide with fly ash addition with different contents of filler was carried out. In this article studies were performed: dynamical mechanical properties, thermal properties and structure research. The profiles of changes in the value of storage modulus $\mathrm{E}^{\prime}$ and tangent of mechanical loss angle $\operatorname{tg} \delta$ depend on the temperature and frequency of vibrations. The crystallinity degree was examined using DSC methodology whereas
\end{abstract}

the structure was analysed by means of the optical microscope. The increase in the value of storage modulus versus temperature and vibration frequency for the samples with addition of filler and the increase in the crystallinity degree and polymer matrix with reduced addition of fly ash were observed. A reduction in size of the structural components was also found, particularly for the composites with filler content.

Adam Gnatowski

gnatowski@ipp.pcz.pl

1 Department of Mechanical Technologies, Czestochowa

University of Technology, Armii Krajowej Ave. 19c,

42-201 Czestochowa, Poland

2 Department of General Building Engineering and Building Physics, Faculty of Civil Engineering, Czestochowa University of Technology, Akademicka 3, 42-201 Czestochowa, Poland 


\section{Graphical Abstract}

Analysis of changes in thermomechanical properties and structure of polyamide modified with fly ash from biomass combustion

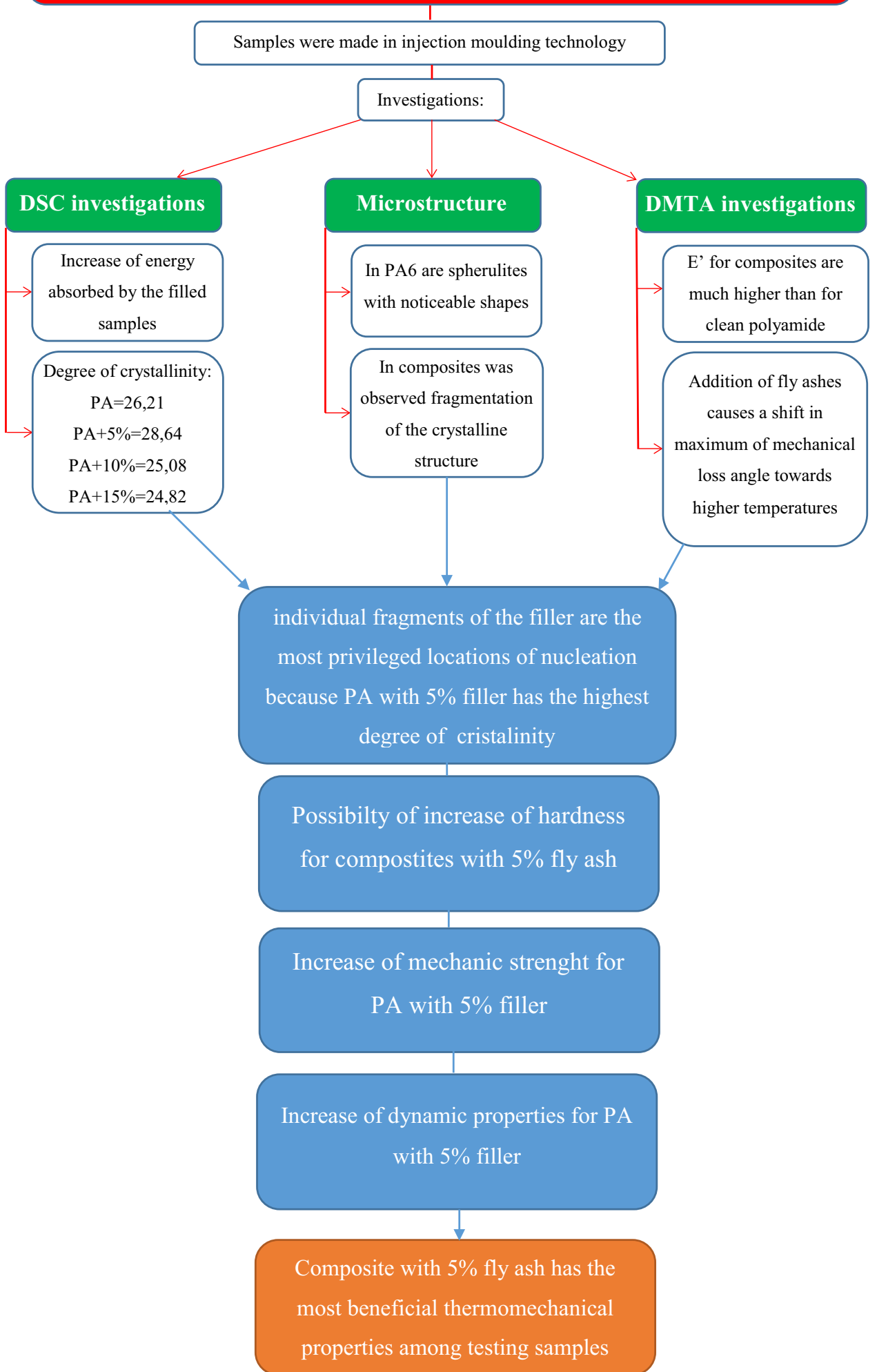


Keywords Composites - Functional properties - Thermal properties $\cdot$ Mechanical properties $\cdot$ Polyamide $\cdot$ Fly ash

\section{Introducion}

Properties of polymers depend on structural factors and conditions of their use. The structural factors include molecular weight, chemical structure of the macromolecules, physical structure of the chain, crystallinity, molecular orientation and presence of additional components. Furthermore, functional conditions are temperature, load time, pressure, type of deformations etc. [1-7]. Properties of polymeric materials can be modified through adding various types of fillers. Type and properties of filler and polymer matrix determine properties of the composite. The research carried out to date allowed for development and introduction for manufacturing of composites with very good strength and thermal properties [1-6].

The paper presents the results of examinations of the polyamide modified with fly ash coming from combustion of biomass in the fluidized-bed furnace. Polyamide is a thermoplastic material which is partially crystalline. It is characterized by high hardness, good dimensional stability and improved machinability. This material has been used in many various industries. Polyamide is used for production of cogwheels, rolls and other parts of machines and equipment, also for the automotive industry [2, 7-9]. Application of filler in the form of fly ash induces changes in functional properties of polyamide. The main purposes of modification of polyamide with fly ash was to improve capability of mechanical vibration damping, improve chemical resistance, dimensional stability, stiffness and changes in many other thermomechanical and functional properties that allow for wider application of the material obtained. Predicting properties and conditions of the use play an important role in planning the composition and preparation of polymeric products [1, 10-17].

This study presents the results of examinations of the effect of addition of fly ash from combustion of biomass in fluidized-bed furnace (which presently is not used and is entirely deposited in the landfill) on the structure and thermal properties of the specimens made of polyamide 6 . The examinations involved thermal analysis (DSC), examination of dynamic properties using the DMTA methodology and supramolecular microstructure.

\section{Materials, Apparatus and Methodology of Research}

Polyamide 6 with commercial name TARNAMID T-27 manufactured by Zakłady Azotowe Tarnów was used in the study. Fly ash manufactured by GDF Suez Energia Polska S.A. from combustion of biomass containing $80 \%$ of waste from wood and $20 \%$ of palm kernel shells in the fluidized-bed furnace. Chemical composition (Table 1) of fly ash was determined using X-ray fluorescence spectroscopy (XRF, ARL spectrometer, Advant'XP). Furthermore, sieve analysis of fly ash was performed using the set of sieves with sieve size of 0.2-0.02 mm (Fig. 1). Mass of the samples was $100 \mathrm{~g}$ and the sieving time was $10 \mathrm{~min}$. Bulk density and tap density of fly ash was determined based on PN-EN-23923-1 and PN-EN-23923-2 standards. Bulk density was $0.43 \mathrm{~g} / \mathrm{cm}^{3}$, whereas tap density was $0.67 \mathrm{~g} / \mathrm{cm}^{3}$. Examinations of the topography and heterogeneity of fly ash surface (Fig. 2) was performed using scanning electron microscope (SEM) manufactured by LEO Electron Microscopy Ltd., equipped in Quantax 200 X-ray spectrometer (EDX) with detector XFlash 4010.

Polyamide before processing was dried in the ZELMET with the heating chamber kc-100/200 at the temperature of $80^{\circ} \mathrm{C}$ by $12 \mathrm{~h}$. Fly ash were covered by silane preparation. The composites were obtained using the extrusion method. Specimens for the tests were injected by means of KRAUSS MAFFEI KM65-160C1 injection molding machine with the feed screw with the diameter

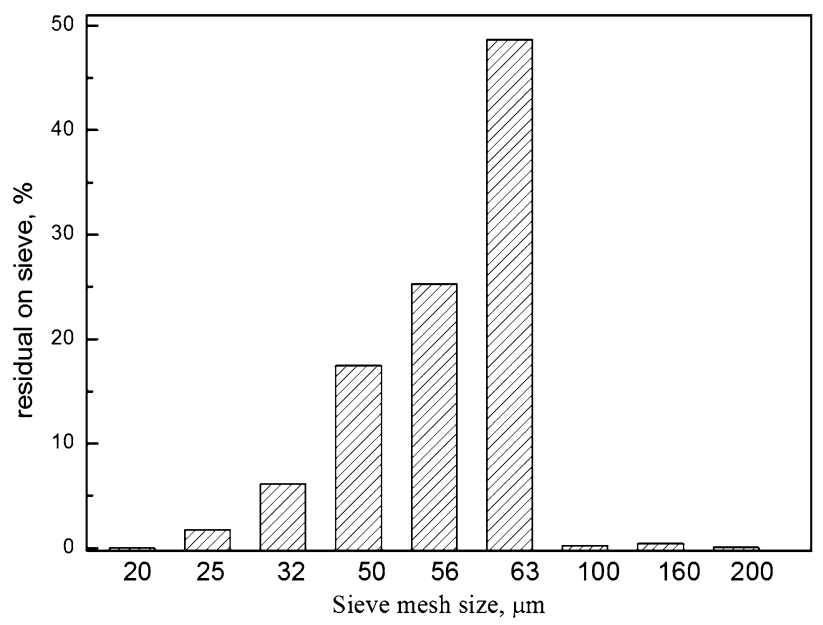

Fig. 1 Particle size distribution of fly ash from biomass combustion
Table 1 The chemical composition of fly ash from the combustion of biomass, $\%$

\begin{tabular}{llllllllllll}
\hline $\mathrm{SiO}_{2}$ & $\mathrm{CaO}$ & $\mathrm{Al}_{2} \mathrm{O}_{3}$ & $\mathrm{MgO}$ & $\mathrm{Fe}_{2} \mathrm{O}_{3}$ & $\mathrm{~K}_{2} \mathrm{O}$ & $\mathrm{Na}_{2} \mathrm{O}$ & $\mathrm{P}_{2} \mathrm{O}_{5}$ & $\mathrm{SO}_{3}$ & $\mathrm{TiO}_{2}$ & $\mathrm{SrO}$ & $\mathrm{Cl}$ \\
\hline 57.54 & 17.26 & 4.82 & 2.32 & 2.94 & 3.93 & 0.39 & 2.01 & 2.71 & 0.30 & 0.04 & 1.06 \\
\hline
\end{tabular}


Fig. 2 SEM microscopic images of fly ash with maps distribution of the dominant elements in this area
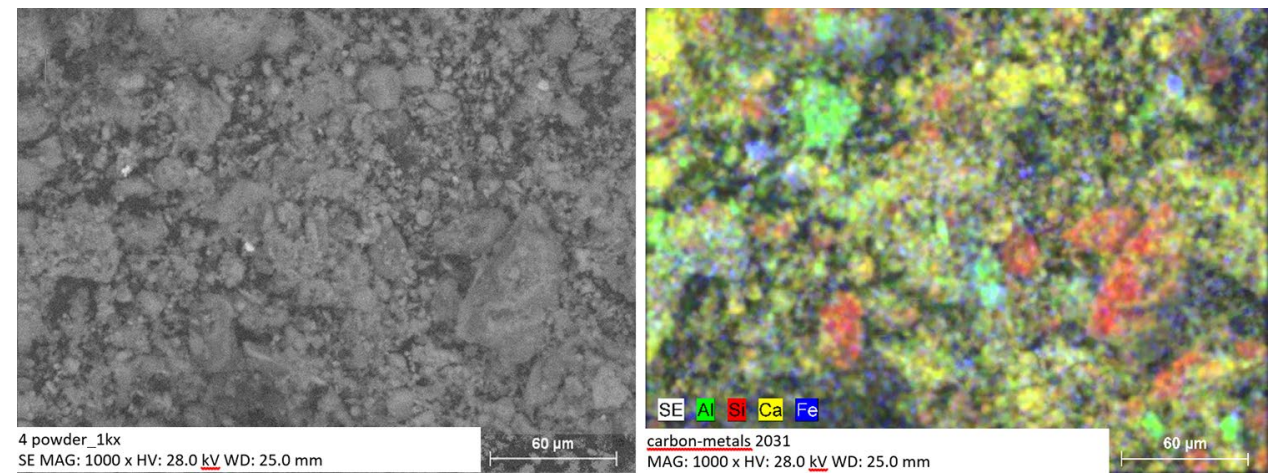

of $30 \mathrm{~mm}$ and L/D ratio of 23 and clamping force of $650 \mathrm{kN}$. The optimal properties of the specimens were obtained for the following injection parameters:

- injection pressure: $100 \mathrm{MPa}$,

- clamping pressure: $45 \mathrm{MPa}$,

- clamping time: $20 \mathrm{~s}$,

- cooling time $15 \mathrm{~s}$,

- mold temperature: $100^{\circ} \mathrm{C}$,

- nozzle temperature $280^{\circ} \mathrm{C}$.

The examinations of thermal properties by means of DSC method were performed using NETZSCH PC 200 scanning microcalorimeter. The DSC curves were recorded during heating of the specimens with the rate of $10^{\circ} \mathrm{C} /$ min within the range of temperature from 40 to $250^{\circ} \mathrm{C}$. In order to minimize the skin-core effect, preparations for DSC examinations were cut out perpendicularly to the direction of flow from the samples obtained using the injection moulding method. Evaluation of the crystallinity degree was based on the software in the PC 200 NETZSCH device. This software allowed for examination of the profile of specimen melting at the given temperature range and determination of the surface area between the thermographic curve and the basic line in the range of endothermic reflex. The mass of specimens ranged from 6 to $11 \mathrm{mg}$. The specimens were weighted by means of the SARTORIUS scales with precision of $0.01 \mathrm{mg}$, internal calibration option and closed weighing space.

Degree of crystallinity of the composites was calculated from the relationship:

$S_{K}=\frac{\Delta H_{m}}{w_{c} \Delta H_{k}} 100 \%$

where $\Delta \mathrm{H}_{\mathrm{m}}$ is the enthalpy of fusion for the material examined, $\Delta \mathrm{H}_{\mathrm{k}}$ is the enthalpy of fusion for the entirely crystalline material, $\mathrm{w}_{\mathrm{c}}$ is the mass fraction of homopolymer added to the composite studied [12].

The microstructure was observed using the Nikon ECLIPSE E 200 optical microscope. The specimen's thickness ranged from 12 to $16 \mu \mathrm{m}$, cut out using the Thermo ELECTRON CORPORATION microtome from the core of the specimens used for DSC examinations.

The examinations of dynamic mechanical properties were performed using NETZSCH DMA 242 device with a holder for three-point free bending of the specimen in the form of a beam with dimensions of $50 \times 10 \times 4 \mathrm{~mm}$ (see Fig. 3).

The specimens in the holder were subjected to sinusoidal force with the frequency of 1 and $10 \mathrm{~Hz}$ with constant amplitude while heating the samples at the rate of $2{ }^{\circ} \mathrm{C} /$ min from -100 to $160^{\circ} \mathrm{C}$. The value of the storage modulus $\mathrm{E}^{\prime}$, loss modulus $\mathrm{E}^{\prime \prime}$ and mechanical loss coefficient $\operatorname{tg} \delta$ were calculated based on the values of forces and strain with regard to the dimensions of the specimens. The results were presented in the form of a chart for changes in storage modulus $\mathrm{E}^{\prime}$ and the angle of mechanical $\operatorname{loss} \operatorname{tg} \delta$ versus temperature.

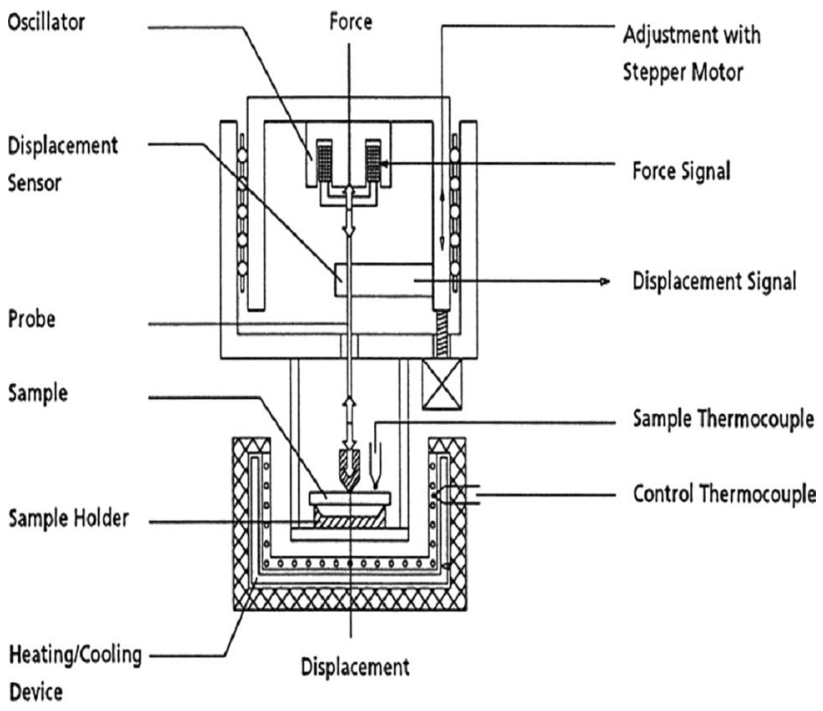

Fig. 3 The scheme of the device for the three-point bending of sample 
Fig. 4 DSC thermogram of polymide 6
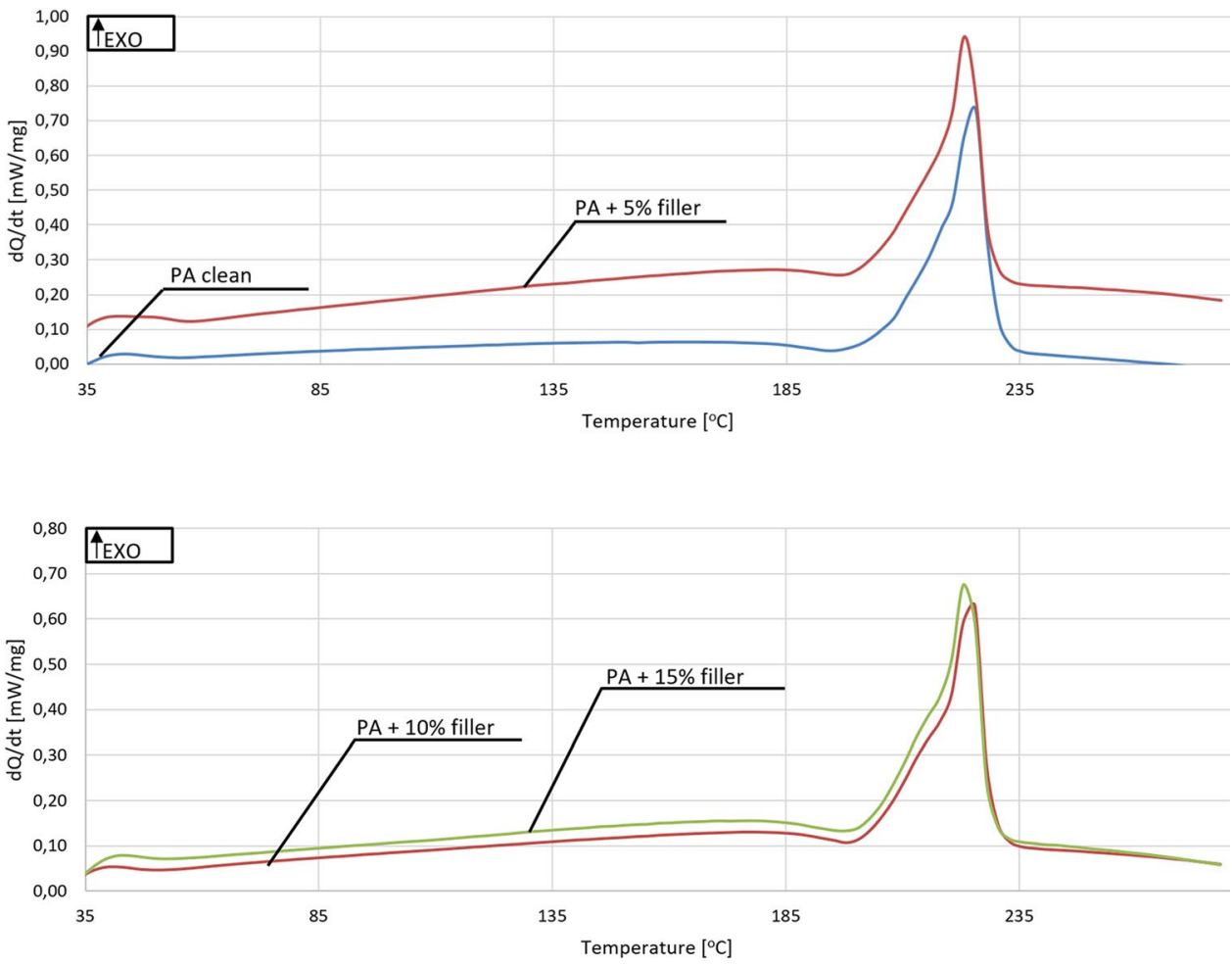

Fig. 5 DSC thermograms of composites

Table 2 The results of DSC investigations obtained from calculations of the Netzsch Proteus programme

\begin{tabular}{llll}
\hline Polymer & $\begin{array}{l}\text { Degree of } \\
\text { crystallinity } \\
(\%)\end{array}$ & Melting range $\left({ }^{\circ} \mathrm{C}\right)$ & $\begin{array}{l}\text { Max. melt } \\
\text { temperature } \\
\left({ }^{\circ} \mathrm{C}\right)\end{array}$ \\
\hline $\mathrm{PA}$ & 26.21 & $219.4-229.4$ & 224.0 \\
$\mathrm{PA}+5 \%$ filler & 28.64 & $218.0-229.3$ & 224.0 \\
$\mathrm{PA}+10 \%$ filler & 25.08 & $220.7-228.5$ & 224.2 \\
$\mathrm{PA}+15 \%$ filler & 24.82 & $220.3-227.7$ & 223.4 \\
\hline
\end{tabular}

\section{Results}

Figures 4 and 5 illustrate DSC thermograms for polyamide 6 and composites with fly ash. Table 2 presents values determined based on the recorded DSC thermographic curves.

After addition of the filler in the form of fly ash, value of energy absorbed by the sample was increasing. The changes in the value of the enthalpy of fusion and mean value of melting temperature of crystallites were recorded. With respect to the percentage content of filler based on the recorded enthalpy of fusion, the values of crystallinity degree was calculated from the relationship (1).

The highest value of the crystallinity degree was recorded for the specimens with $5 \%$ content of fly ash. The increase in the content of filler resulted in the decrease in enthalpy of fusion and the range of melting temperature for the crystalline phase was narrowed. Furthermore, the maximal melting temperature was insignificantly changed.

These changes reflect the reinforcing role of the filler particles contained in PA6. These data may also point to the increased capability of composites with lower content of filler to crystallize.

The increase in the crystalline phase recorded for the specimens made of polyamide 6 with $5 \%$ of filler was likely to be caused by formation of heterogenic centres of nucleating around filler while cooling in injection mold. With greater content of filler, the reduced nucleation causes the opportunities for further growth of the crystalline phase of the polymer matrix. Some fillers introduced to semicrystalline polymer increase the crystalline temperature in the matrix and lead to the reduction in the crystallites' size and lower content of the crystalline phase while performing the role of a nucleating factor, on which heterogeneous crystallization nuclei are formed. This might cause the increase in hardness and mechanical strength and improvement in dynamic properties of the composite with $5 \%$ content of filler, which was supported by the results of the DMTA examinations.

In the case of heterogeneous nucleation that occurs during phase transition, the most privileged locations of nucleation are aggregates or individual fragments of the filler, which was also demonstrated by the results of microstructural examinations. Compared to other semicrystalline materials, the structure of polyamide 6 is characterized by fine grains $[9,12]$, with spherulites. 
With noticeable shapes but small dimensions (see Fig. 6a). The examinations of the structure of polyamide 6 composites by means of optical microscope revealed fragmentation of the crystalline structure (Fig. 6b-d). The structure is the most noticeable and organized for polyamide 6 . With addition of the filler, polyamide structure changes and a reduction in structural components was observed, particularly in the case of greater filler content.

Figure 7 illustrates changes in the function of temperature of storage modulus $\mathrm{E}^{\prime}$ and coefficient of mechanical

Fig. 6 Microstructure observed under an optical microscope at a magnification of a PA6, $\mathbf{b}$ PA $6+5 \%$ filler, c PA $6+10 \%$ filler, d PA $6+15 \%$ filler
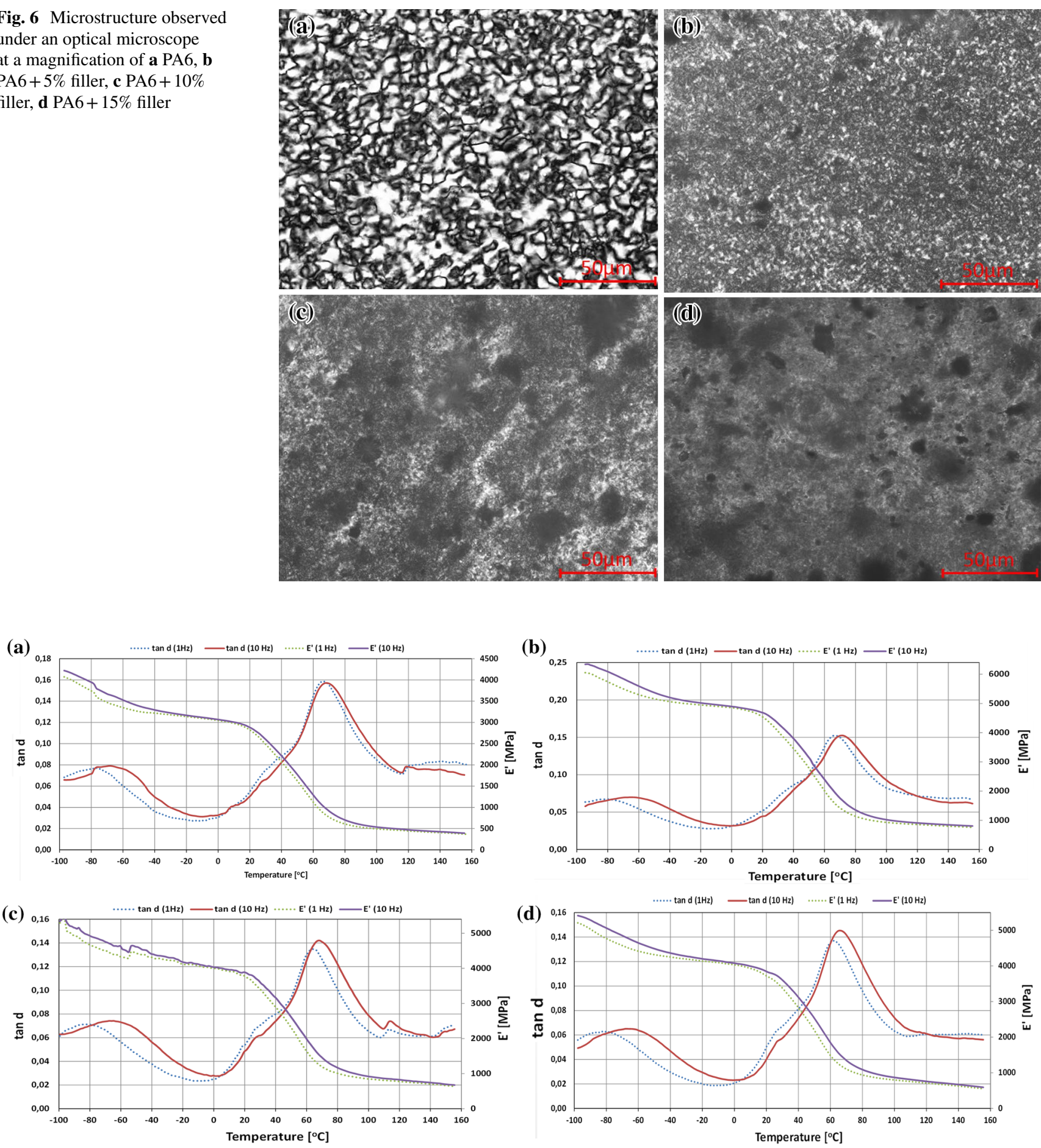

Fig. 7 Changes in the function of temperature of storage modulus $E^{\prime}$ and coefficient of mechanical loss a PA6, b PA6+5\% filler, $\mathbf{c}$ PA6+10\% filler, $\mathbf{d}$ PA $6+15 \%$ filler 
loss for the composites obtained depending on the filler content. In each case, the first reduction in $\mathrm{E}^{\prime}$ value corresponds to relaxation processes. The increase in the temperature leads to the second, substantial reduction in storage modulus that corresponds to the process of relaxation of amorphous regions of PA6. Within the range of temperature above vitrification temperature $\mathrm{Tg}$, corresponding to the transition from the vitreous into the highly-plastic state, a flat profile zone can be observed for the curves. In the area of temperatures below vitrification temperature, the composite is in the vitreous state and it is hard and brittle. In the vitreous area, thermal energy is insufficient to overcome the potential barrier for transition and rotational movements of the molecule segments. The system remains in the state of non-equilibrium thermodynamics. The increase in the temperature leads to a reduction in the value of module for composites. The material is in the area of vitrification transition, where loss tangent reaches maximum values in the vitrification area for the set frequency of deformation of 1 and $10 \mathrm{~Hz}$. In the area of vitrification transition Brownian motion is initiated in the molecular chain. Thermal energy becomes comparable with the barrier of potential energy for chain rotation. Near the temperature of vitrification transition, viscoelastic properties change very fast with time and the changing temperature.

In the studied range of temperature (from -150 to $160^{\circ} \mathrm{C}$ ), values $\mathrm{E}^{\prime}$ for the composites containing fly ash from biomass were significantly higher than the values of $\mathrm{E}^{\prime}$ for PA6 without filler. The profile of changes in storage modulus versus temperature is similar for both frequencies studied (1 and $10 \mathrm{~Hz})$. Storage modulus for the sample containing $5 \mathrm{wt} \%$ of filler at temperature of $25^{\circ} \mathrm{C}$ is $4234 \mathrm{MPa}$ and is by $60 \%$ higher than $\mathrm{E}^{\prime}$ for polyamide 6 . Therefore, the amorphous phase of the composite with $5 \mathrm{wt} \%$ of filler shows the strongest reinforcement with the particles of fly ash from biomass, which demonstrates higher degree of dispersion of filler in the specimen compared to other composites. It should be emphasized that the composites containing 10 and $15 \mathrm{wt} \%$ of filler are characterized by similar and greater value of $\mathrm{E}^{\prime}$ over the whole temperature range compared to non-filled polymer. Therefore, particles of filler have a substantial reinforcing effect on the material for all compositions studied. The temperature and intensity of relaxation has an effect on the crystallites' size. The higher the temperature and higher relaxation intensity, the greater crystallites' size. These changes are usually accompanied by the increase in the crystallinity degree [17]. Addition of fly ash causes a shift in maximum of mechanical loss angle towards higher temperatures and reduces with the shift towards lower temperatures with the increase in the content of fly ash from biomass. These shifts in peaks result from the increasing stabilization of the composites that result from the immobilization of the fragments of PA6 crystallites by the filler particles.

The maximum of the tangent of mechanical loss angle in the range of negative temperatures connected with the movements of chain fragments in the amorphous area or vitrification temperature [17, 18]. Addition of filler leads to the shift in this relaxation towards higher temperature, which suggests immobilization of fragments of PA6 chains by fly ash.

\section{Conclusion}

Addition of fly ash from biomass combustion containing over $57 \% \mathrm{CaO}$ and $17 \% \mathrm{CaO}$ and substantial amounts of alkaline oxides $(4.32 \%)$ to polyamide 6 has a beneficial effect on dynamic mechanical and thermal properties of the material. Silane preparation improves compatibility of the polymer matrix and filler. It was found based on the DSC examinations of the composite specimens that crystalline phase of the polymeric matrix was reduced except for the material with lower filler content, whereas the range of melting temperature was not changed substantially. DSC analysis revealed that addition of fly ash from biomass combustion to PA6 causes only insignificant changes in melting temperature. Addition of fly ash from biomass combustion in small amount significantly increased the crystallinity degree and stiffness of composites of polymer with fly ash. It was found that the particles of filler added in the content of 5\% have higher reinforcing effect that the particles added with higher amounts.

In the range of filler content studied, the effect of this parameter on the value of phase transition temperatures for the composites of polymer with fly ash is insignificant. This can be explained by the crystalline structure which is limited by filler particles during composite cooling. The effect of greater amount of filler is smaller, which results in lower reinforcing effect of the nanofiller. The composites studied are characterized by better thermomechanical properties compared to PA6 without filler, whereas the composites with the amount of $5 \%$ are characterized by higher storage modulus, mainly in the range of temperatures of -100 to $80^{\circ} \mathrm{C}$. The significant effect of filler on the microstructure of the materials studied was also found, with the most substantial changes recorded for the greatest $(15 \%)$ content of filler.

Open Access This article is distributed under the terms of the Creative Commons Attribution 4.0 International License (http:// creativecommons.org/licenses/by/4.0/), which permits unrestricted use, distribution, and reproduction in any medium, provided you give appropriate credit to the original author(s) and the source, provide a link to the Creative Commons license, and indicate if changes were made. 


\section{References}

1. Singh SB, Ray S (2003) J Mater Process Technol 143-144:623-628

2. Rosato DV, Rosato MG, Schott NR (2011) Plastics technology handbook. Exeter, Momentum Press

3. Fazal A, Arif M (2003) J Mater Process Technol 136:120-138

4. Papathanasiou TD, Kamal MR (1993) Polym Eng Sci 33:400-409

5. Gnatowski A, Koszkul J (2005) J Mater Process Technol 162-163:52-58

6. Ehrenstein GW (2001) Polymeric materials. Hanser Publishers, Munich, pp 1-12

7. Pramoda KP, Liu T (2004) J Polym Sci Part B 42(10):1823-1830

8. Xie S, Zhang S, Wang F, Liu H, Yang M (2005) Polym Eng Sci 45(9):1248-1253

9. Gnatowski A (2007) J Polym Eng 27(6-7):507-524
10. Matabola KP, de Vries AR, Luyt AS, Kumar R (2011) Express Polym Lett 7:635-642. doi:10.3144/expresspolymlett.2011.61

11. Wetton RE, De Blok R, Corish PJ (1991) Intern Polym Sci Technol 18:163-166

12. Alonso M, Velasco JI, de Saja JS (1997) Eur Polym J 33(3):255-262

13. Jeziórska R, Ewierz-Motysia B, Zielecka M, Studziñski M (2009) Polimery 54:727

14. Ray SS, Okamoto M: (2003) Prog Polym Sci 28:1539

15. Wunderlich B (2003) Prog Polym Sci 28:383

16. Jeziórska R, Zielecka M, Szadkowska A, Wenda M, Tokarz L (2012) Polimery 3:192-203

17. Popli R, Glotin M, Mandelkern L (1984) J Polym Sci Part B 22:407

18. Cerrada ML, Benavente R, Perez E (2001) Macromol Chem Phys 202:2686 